\title{
Prophylactic treatment of ischemic stroke with Coffea arabica in rats: A preliminary study
}

\author{
Arshia Batool Khanum ${ }^{1}{ }^{*}$, Lubna Shakir ${ }^{1}$, Zaka-ur-Rehman ${ }^{2}$, Tanveer Ahmed Khan ${ }^{3}$, Komal Najam ${ }^{1}$, \\ Nasira Saeed ${ }^{1}$, Mahtab Ahmed Khan ${ }^{4}$, Anam Nazeer ${ }^{1}$, Tayyaba Nazir ${ }^{1}$, Shawana Aslam ${ }^{1}$
}

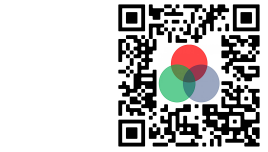

Use your smartphone to scan this QR code and download this article

${ }^{1}$ Department of Pharmacy, Hajvery

University, Lahore, Pakistan

${ }^{2}$ Faculty of Pharmacy, University of Lahore, Lahore, Pakistan

${ }^{3}$ National Institute of Health, Islamabad, Pakistan

${ }^{4}$ University of Lahore, Lahore, Pakistan

Correspondence

Arshia Batool Khanum, Department of Pharmacy, Hajvery University, Lahore, Pakistan

Email: arshia.batool16@gmail.com

History

- Received: Mar 24, 2020

- Accepted: May 11, 2020

- Published: May 25, 2020

DOI : 10.15419/bmrat.v7i5.604

\section{Check for updates}

\section{Copyright}

( $)$ Biomedpress. This is an openaccess article distributed under the terms of the Creative Commons Attribution 4.0 International license.

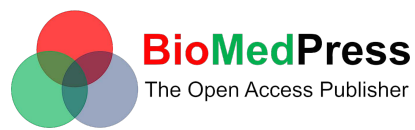

\begin{abstract}
Introduction: Ischemic stroke is the third leading cause of death worldwide. The purpose of the current study was to assess the preliminary effects of Coffea arabica (CA) in experimentally-induced stroke in an animal model in the context of neuroprotection. The study was also designed to document the prophylactic use of CA in patients experiencing stroke symptoms. Methods: A total of 25 male albino rats, 12 months of age, were purchased from the local market. They were acclimatized for seven days and divided into 5 groups. Each group consists of 5 subjects. Each subject was trained on a specific test for behavioral assessment. Behavioral modulation of each rat was performed using four tests, namely cylinder test, staircase test, forelimb flexion test, and pasta test. All the tests were performed as per standard criteria at the $4^{\text {th }}, 8^{\text {th }}, 12^{\text {th }}$, and $14^{\text {th }}$ day of drug administration. The subjects were administered with caffeine $(2.4 \mathrm{mg} / \mathrm{kg})$ and CA $(100 \mathrm{mg} / \mathrm{kg}$ and 200 $\mathrm{mg} / \mathrm{kg}$ extract) doses for 14 days to assess the prophylactic use of CA. After 14 days of treatment, rats were subject to ischemic stroke induction using the middle cerebral artery ligation method. All four tests used for behavior modulation were applied at 24, 48, and 72 hours intervals of postsurgery. The subjects were further sacrificed for histopathological investigations. Statistical analysis was performed with SPSS (V. 22) software using one-way ANOVA. Results: Our findings suggest that treatment with CA, $100 \mathrm{mg} / \mathrm{kg}$ and $200 \mathrm{mg} / \mathrm{kg}$ orally, decreases the infarct volume. However, there are not many considerable differences that were found in both doses. Histopathological investigations revealed characteristic structural changes occurring in both gray and white brain regions, depending on the severity, location, and duration of the ischemic stroke. Conclusion: CA is a harmless and active mediator in the dissolution of blood clots and the recovery of stroke in rats. It is an agent that has been found to be efficient for brain activity with few side effects and behavioral modifications.
\end{abstract}

Key words: Coffea arabica, ischemic stroke, Forelimb flexion, Pasta, Staircase

\section{INTRODUCTION}

Stroke is generally well-defined as an abnormality of blood supply to a principal area of the brain. This primary abnormality might be a diminution of nutrients (commonly ischemia) or hemorrhage; the abnormality may vary in time interval and extent, producing an enormous number of temporary or permanent neurological defects ${ }^{1}$. Acute ischemic stroke is the third primary cause of death in developed countries and Europe ${ }^{2}$. It is one of the most recurring causes of disability around the globe ${ }^{3}$. Irrespective of pathophysiological understanding of cerebral ischemia and its advances in modern science, there are minimal numbers of pharmacotherapy protocols ${ }^{3}$. Only Recombinant Tissue-Plasminogen Activator (rt-PA) for thrombolysis has been approved for practice in the management of this disease ${ }^{4}$. Various Chinese ${ }^{5}$ and herbal medicines, including alternative therapies ${ }^{6}$, have been used in the treatment of ischemic stroke for a long time; one of these significant medicinal plants is Coffea arabica (CA).

$\mathrm{CA}$ is a species of Coffea, and is rich in phytochemical constituents like caffeine, trigonelline, chlorogenic acids, and sucrose ${ }^{7}$. Several studies have reported its anti-inflammatory effects ${ }^{8}$ and anti-fungal properties $^{9}$.

The purpose of the current study was to assess the preliminary effects of CA in experimentally-induced stroke in an animal model in the context of neuroprotection. The study was also designed to document the prophylactic use of CA in patients experiencing stroke symptoms.

\section{MATERIALS - METHODS}

\section{Animals}

A total of 25 male albino rats (12 months of age) were purchased. All subjects were weighed for dose and food administration. The weight variation ranged 
from 290 to $300 \mathrm{~g}$. The subjects were kept in standard confinement (length $=450 \mathrm{~mm} \times$ width $=340 \mathrm{~mm} \times$ height $=210 \mathrm{~mm}$ ) for animal housing; animals were kept in a controlled environment at standard conditions of temperature $\left(22 \pm 1^{\circ} \mathrm{C}\right.$ ) and humidity (40 to $60 \%)$. Animals were exposed to twelve hours of light and dark cycles.

\section{Preparation of Coffea arabica (CA) extract}

Aqueous extract of CA was prepared through mechanical pressing and solvent extraction methods using soxhlet apparatus and rotary vacuum evaporator.

\section{Method of ischemic stroke induction}

Rats were anesthetized with Ketamine. Blood pressure and oxygen supply were monitored. Ischemic stroke was induced using the ligation technique (Figure 1) of the Middle Cerebral Artery Occlusion (MCAO) method $^{10}$.

\section{Treatment protocol}

Rats were acclimatized for 7 days, and the bodyweight of each subject was recorded. They were divided into 5 groups ( $n=5$ per group). Each rat was trained on a specific test for behavioral assessment. Behavioral modulation (Figure 2) of each rat was performed using four tests, namely cylinder test ${ }^{11}$, staircase test ${ }^{12}$, forelimb flexion test, and pasta test ${ }^{13}$. All the tests were performed as per standard criteria at the $4^{t h}, 8^{t h}$, $12^{\text {th }}$, and $14^{\text {th }}$ day of drug administration.

The subjects were administered with caffeine and CA doses (Table 1) for 14 days to assess the prophylactic use of CA. We used two different doses to assess its efficacy. In our pilot study, $300 \mathrm{mg}$ and $500 \mathrm{mg} / \mathrm{kg}$ doses of CA were found to be fatal and possessed adverse effects. Therefore, we used these two doses, 100 $\mathrm{mg} / \mathrm{kg}$ and $200 \mathrm{mg} / \mathrm{kg}$, in our current study. All the subjects received an oral dose once a day.

\section{Methods for evaluation}

Time latency (seconds) was observed in forelimb flexion and staircase tests. The use of impaired forelimbs in cylindrical test and the number of falls in pasta test were observed. The latency was observed for time and limb movement. Histopathology examination was performed by slicing of the brain, and this was further confirmed by brain staining with 2,3,5-Triphenyl Tetrazolium Chloride (TTC) reagent.

\section{Statistical analysis}

Statistical analysis was performed using the Statistical Package for Social Sciences software (version 22.0). One-way analysis of variance (ANOVA) was applied using a Tukey range post-hoc test. The level of significance was considered as $\mathrm{p}<0.05$.

\section{Ethical Statement}

The current study was approved by the Committee on Animal Ethics, Hajvery University, Lahore, Pakistan, under the ethical approval letter no. HU-EC-07-2017.

\section{RESULTS}

The current study was aimed to assess the neuroprotective action of CA in a rat model of ischemic stroke. Animals were acclimatized for one week, and behavioral modelling was performed. This behavioral modelling was conducted to evaluate a measure of performance at a latency period of $4^{\text {th }}, 8^{\text {th }}$, $12^{\text {th }}$, and $14^{\text {th }}$ day during Caffeine and CA administration (Figure 3). All the subjects in the study groups showed normal behavior and accomplished specific tasks. However, few subjects in both control and sham groups responded spontaneously while performing forelimb flexion and staircase test. This impulsive behavior may owe a change in their physiological function. It was also observed that rats receiving CA became slightly aggressive; this observation warrants further evaluation in future research studies. The mean latency time in cylinder test of control, sham, caffeine, CA $100 \mathrm{mg} / \mathrm{kg}$, and CA $200 \mathrm{mg} / \mathrm{kg}$ groups were noted as 6.6, 5.4, 7.1, 5.2, and 6.8 seconds, respectively. The mean latency time of forelimb flexion group was observed as 12.8, 13.1, 12.5, 11.6, and 12.2 seconds for the control, sham, caffeine, CA 100 $\mathrm{mg} / \mathrm{kg}$, and CA $200 \mathrm{mg} / \mathrm{kg}$ groups, respectively. Observations (mean) of the staircase test were recorded as $9.4,10.4,8.4,9.1$, and 9.8 seconds for the respective groups. The results (movement) monitored in the pasta test were documented as 4.1, 3.9, 4.0, 3.6, and 4.4 seconds, respectively. Consequently, we found no statistically significant difference ( $p=0.271$ ) in the rats' behavior among the groups (Figure 3). All subjects were found to be under the appropriate conditions for surgical procedures.

Ischemic stroke was induced through the MCAO method. All mentioned tests were applied after induction of stroke at intervals of 24, 48, and 72 hours.

\section{Cylinder test}

Subjects were assisted to perform cylinder test. There was a significant statistical difference found between 

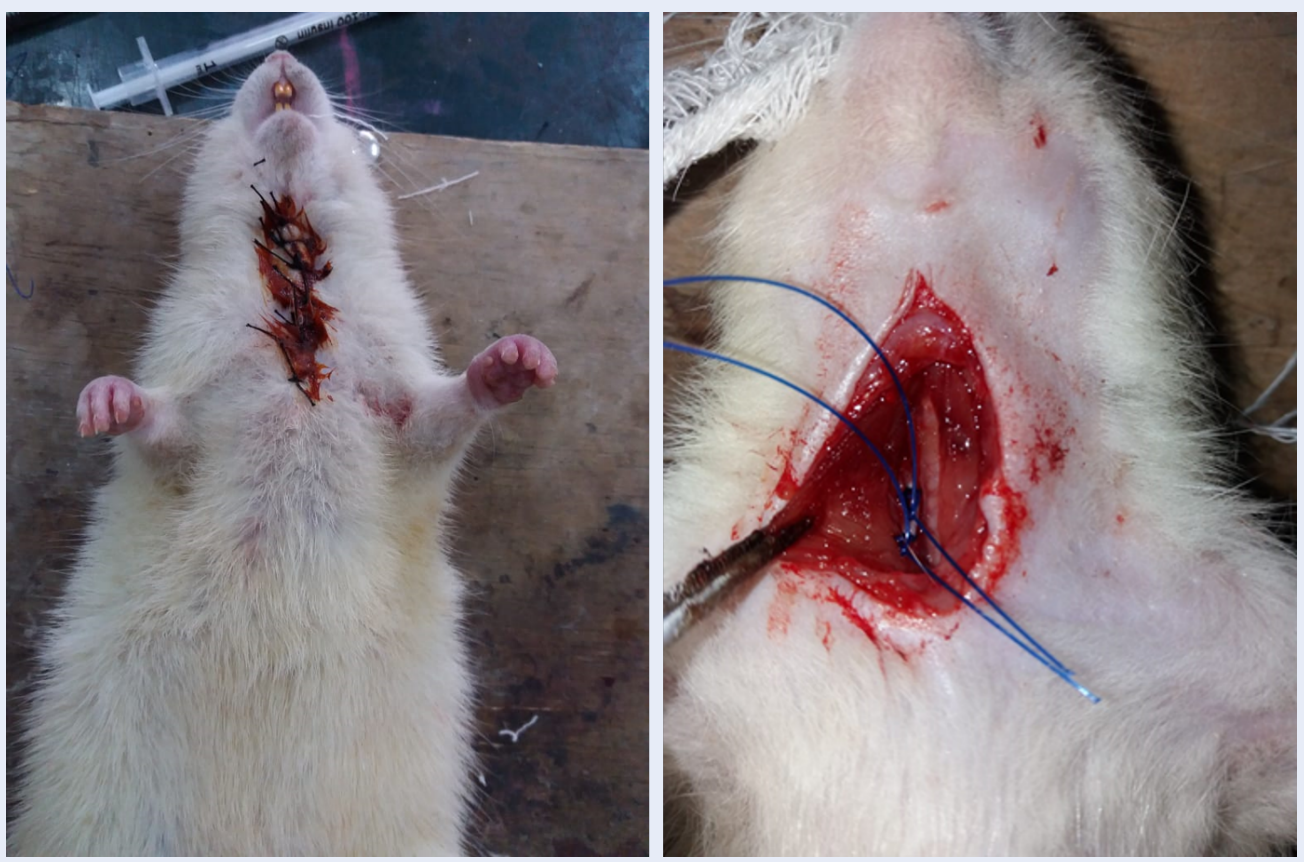

Figure 1: Induction of ischemic stroke. The designed ischemic stroke was induced using the ligation technique of the middle cerebral artery occlusion method.

Table 1: Dose regimen (sample size, $n=5$ )

\begin{tabular}{|c|c|c|c|c|c|c|c|c|c|c|c|c|c|c|c|}
\hline Grou & Dose & & & & & & & & ays & & & & & & \\
\hline & & 1 & 2 & 3 & 4 & 5 & 6 & 7 & 8 & 9 & 10 & 11 & 12 & 13 & 14 \\
\hline Contı & $\begin{array}{l}\text { Norn } \\
\text { salin }\end{array}$ & $\sqrt{ }$ & $\sqrt{ }$ & $\sqrt{ }$ & $\sqrt{ }$ & $\sqrt{ }$ & $\sqrt{ }$ & $\sqrt{ }$ & $\sqrt{ }$ & $\sqrt{ }$ & $\sqrt{ }$ & $\sqrt{ }$ & $\sqrt{ }$ & $\sqrt{ }$ & $\sqrt{ }$ \\
\hline Sham & Nil & - & - & - & - & - & - & - & - & - & - & - & - & - & - \\
\hline Caffej & $\begin{array}{l}2.4 \\
\mathrm{mg} / \mathrm{k}\end{array}$ & $\sqrt{ }$ & $\sqrt{ }$ & $\sqrt{ }$ & $\sqrt{ }$ & $\sqrt{ }$ & $\sqrt{ }$ & $\sqrt{ }$ & $\sqrt{ }$ & $\sqrt{ }$ & $\sqrt{ }$ & $\sqrt{ }$ & $\sqrt{ }$ & $\sqrt{ }$ & $\sqrt{ }$ \\
\hline $\begin{array}{l}\mathrm{CA} \\
100 \\
\mathrm{mg} / \mathrm{k}_{\mathbf{i}}\end{array}$ & $\begin{array}{l}100 \\
\mathrm{mg} / \mathrm{k}\end{array}$ & $\sqrt{ }$ & $\sqrt{ }$ & $\sqrt{ }$ & $\sqrt{ }$ & $\sqrt{ }$ & $\sqrt{ }$ & $\sqrt{ }$ & $\sqrt{ }$ & $\sqrt{ }$ & $\sqrt{ }$ & $\sqrt{ }$ & $\sqrt{ }$ & $\sqrt{ }$ & $\sqrt{ }$ \\
\hline $\begin{array}{l}\mathrm{CA} \\
200 \\
\mathrm{mg} / \mathrm{k}\end{array}$ & $\begin{array}{l}200 \\
\mathrm{mg} / \mathrm{k}\end{array}$ & $\sqrt{ }$ & $\sqrt{ }$ & $\sqrt{ }$ & $\sqrt{ }$ & $\sqrt{ }$ & $\sqrt{ }$ & $\sqrt{ }$ & $\sqrt{ }$ & $\sqrt{ }$ & $\sqrt{ }$ & $\sqrt{ }$ & $\sqrt{ }$ & $\sqrt{ }$ & $\sqrt{ }$ \\
\hline
\end{tabular}

the control and sham group ( $\mathrm{p}=0.001)$, and the very least statistical significance was observed between CA $100 \mathrm{mg} / \mathrm{kg}$ and CA $200 \mathrm{mg} / \mathrm{kg}$ groups ( $\mathrm{p}=0.645$ ). Statistical results were not encouraging in comparison of the control and CA $100 \mathrm{mg} / \mathrm{kg}$ group ( $\mathrm{p}=$ 0.295). However, these insignificant statistical results show a significant effect of the CA $100 \mathrm{mg} / \mathrm{kg}$ dose. Moreover, a higher dose of $200 \mathrm{mg} / \mathrm{kg}$ minimally exhibits the reversal phenomenon of the ischemic stroke (Figure 4).

\section{Forelimb flexion test}

Our study subjects were also assessed for forelimb extension. Statistically significant differences were found among CA $100 \mathrm{mg} / \mathrm{kg}(5.933+0.733)$, control $(12.800+0.000)$, and sham $(0.600+0.115)$ groups after 24,48 , and 72 hours intervals $(\mathrm{p}=0.000)$, respectively (Figure 5). However, CA $100 \mathrm{mg} / \mathrm{kg}$ dose $(5.933+0.733)$ and CA $200 \mathrm{mg} / \mathrm{kg}$ dose $(4.666+0$. $635)$ groups were comparatively insignificant in their differences $(p=0.442)$. Moreover, CA powder at the 

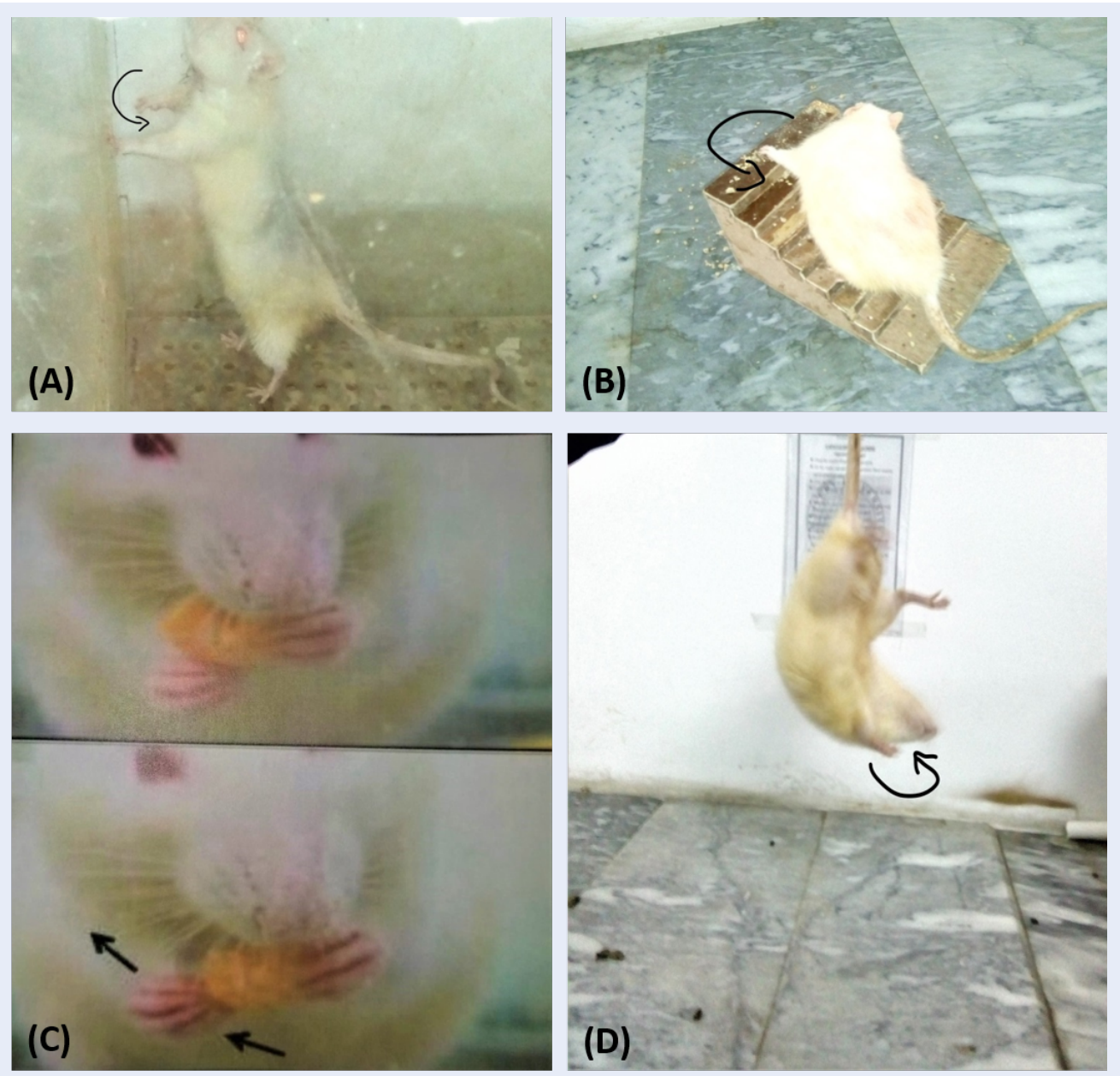

Figure 2: Behavioural modulation of rats. All four tests entitled (A) cylinder test, (B) staircase test, (C) pasta test, and (D) forelimb flexion test were performed on rats to incorporate behaviour modulation for our study under standard laboratory conditions.

$100 \mathrm{mg} / \mathrm{kg}$ dose was more effective at inducing or alleviating stroke at all levels of treatment intervals. On the other hand, CA $200 \mathrm{mg} / \mathrm{kg}$ dose $(4.666+0.635)$ showed less improvement of stroke recovery.

\section{Staircase test}

Rats were subject to the staircase test. The results were statistically significant among all groups $(p=0.000)$. However, CA $100 \mathrm{mg} / \mathrm{kg}$ group was significantly different from sham $(\mathrm{p}=0.000)$ and caffeine $(\mathrm{p}=0.030)$ groups. On contrary, it was less different from the control $(\mathrm{p}=0.143)$ and CA $200 \mathrm{mg} / \mathrm{kg}$ dose $(\mathrm{p}=0.174)$ groups. These observations showed that the effect of CA $100 \mathrm{mg} / \mathrm{kg}$ dose was almost similar to the control group. It also revealed that both doses show almost equivalent response (Figure 6).

\section{Pasta test}

The pasta test was performed on subjects receiving established treatment. Statistical analysis showed significantly different results between control $(4.200+$ $0.577)$ and sham $(18.133+0.982)$ groups $(\mathrm{p}=0.000)$. We documented similar observations between sham $(\mathrm{p}=0.000)$ and CA $100 \mathrm{mg} / \mathrm{kg}$ dose $(\mathrm{p}=0.000)$ group. The results revealed that CA $100 \mathrm{mg} / \mathrm{kg}$ dose is more protective to MCAO-induced stroke, than compared to caffeine and CA $200 \mathrm{mg} / \mathrm{kg}$ (Figure 7).

\section{Histopathological studies}

The histopathological significances of ischemic stroke are multifaceted. Their outcomes may lead to several deficits, including severe motor and cognitive disturbances. The histopathological consequences in our study show typical structural changes in both gray 


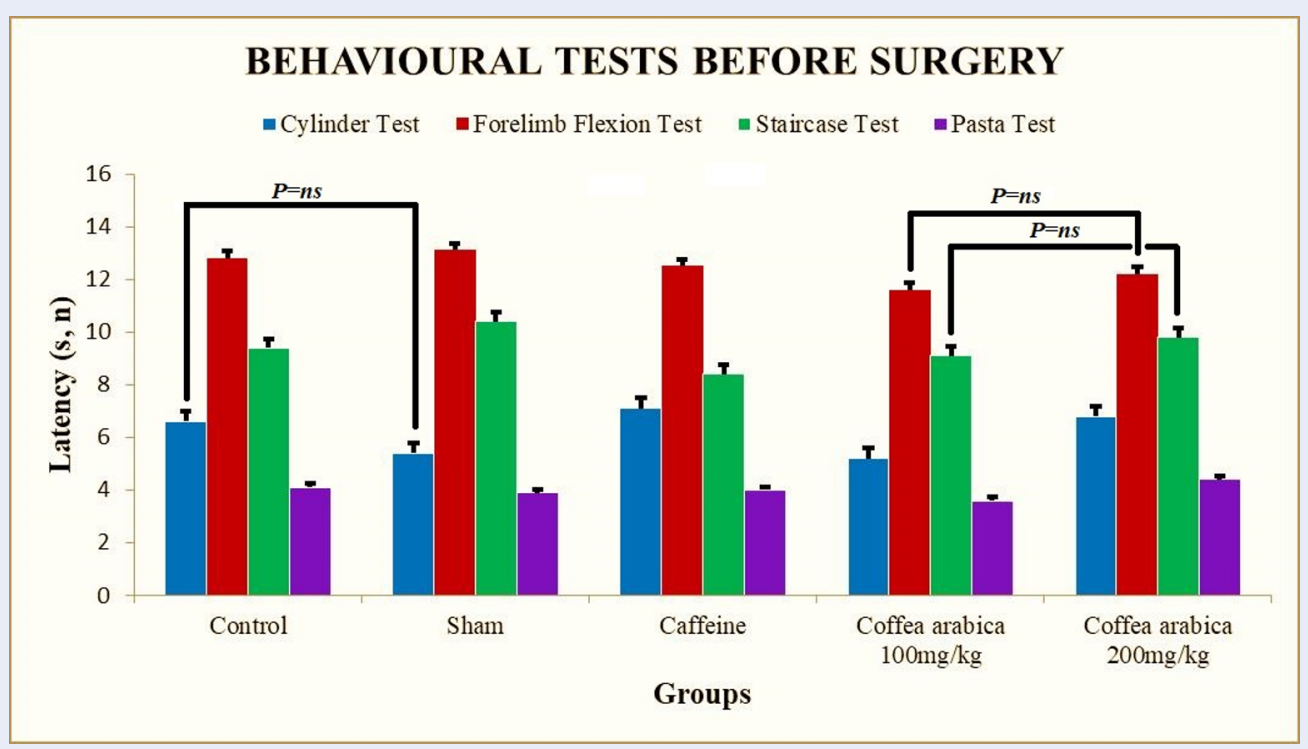

Figure 3: Graphic representation of behavioural tests before induction of ischemic stroke. All four tests were applied to each group before performing surgery. Results indicate that all groups responded almost alike.

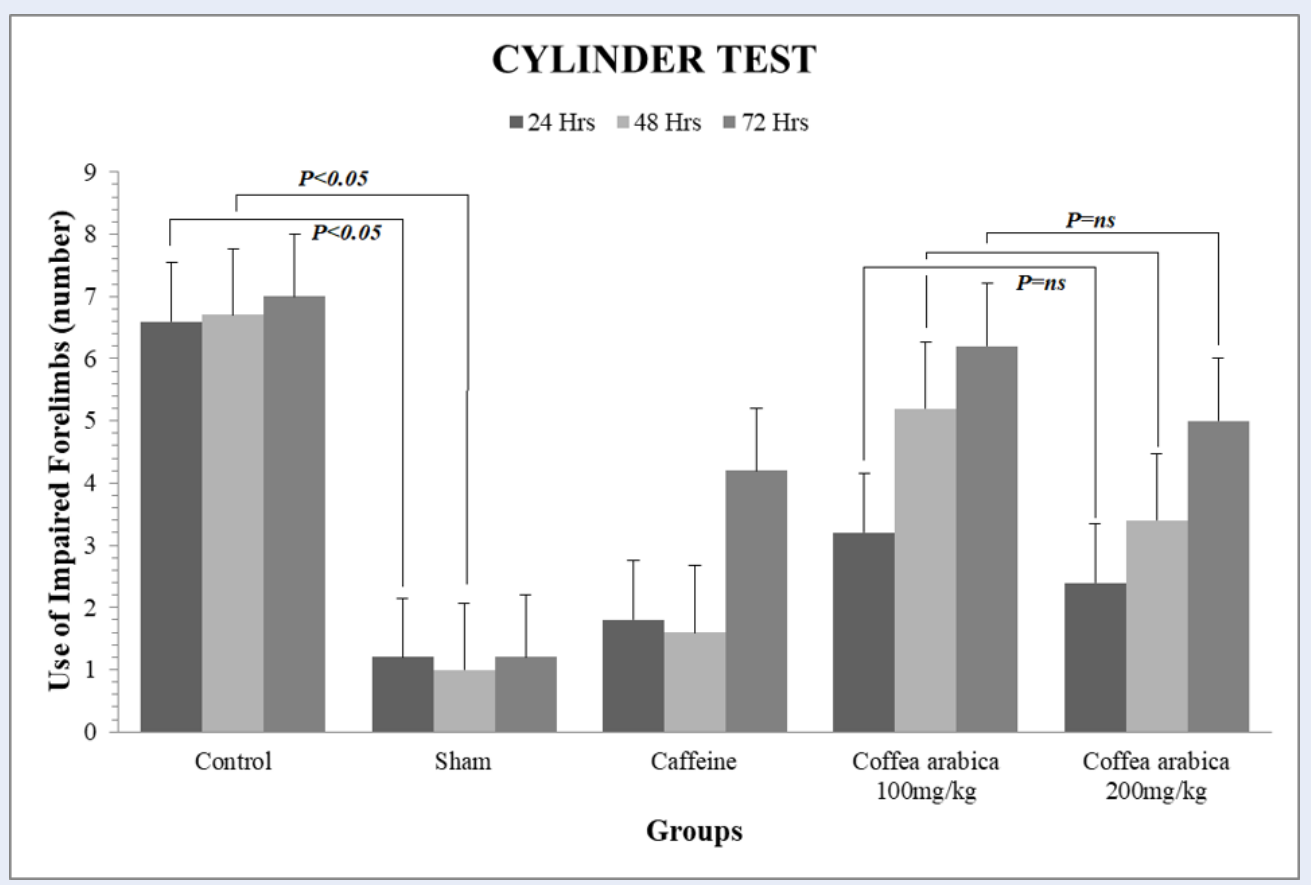

Figure 4: Graphical profiling of cylinder test. The cylinder test was performed after 24,48 , and 72 hours of stroke induction to evaluate the spatial patterns of central nervous system disorders. The figure reveals that the animal group receiving $100 \mathrm{mg} / \mathrm{kg}$ of Coffea arabica dose responded better against stroke in comparison to other groups, and its behaviour pattern is closed to the control group. 


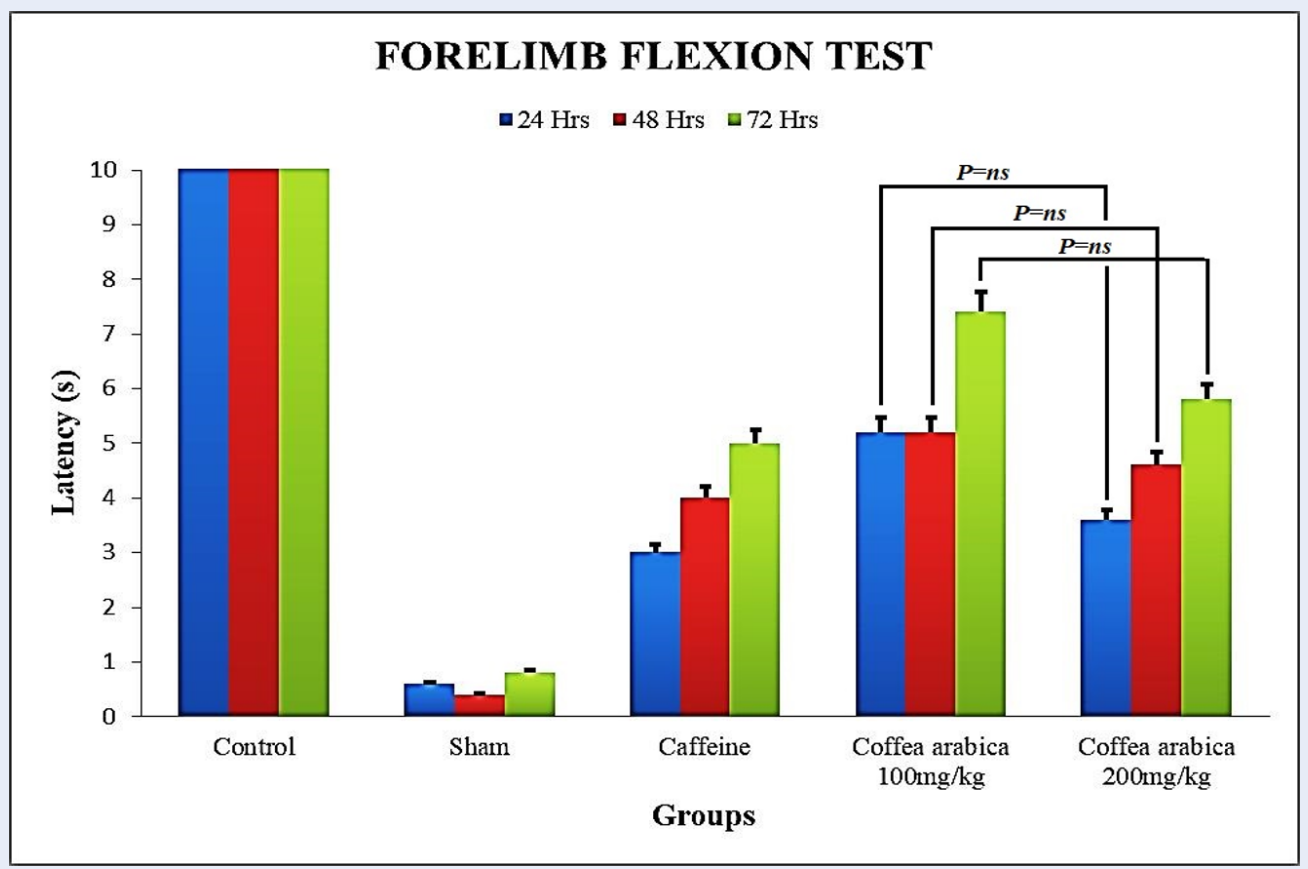

Figure 5: Graphical outlining of forelimb flexion test. Forelimb flexion test was executed after 24,48 , and 72 hours of stroke induction to detect the neurological insufficiencies. The figure shows that animal group receiving $100 \mathrm{mg} / \mathrm{kg}$ of Coffea arabica dose reacted better as compared to other groups, and its behaviour pattern is closed to the control group.

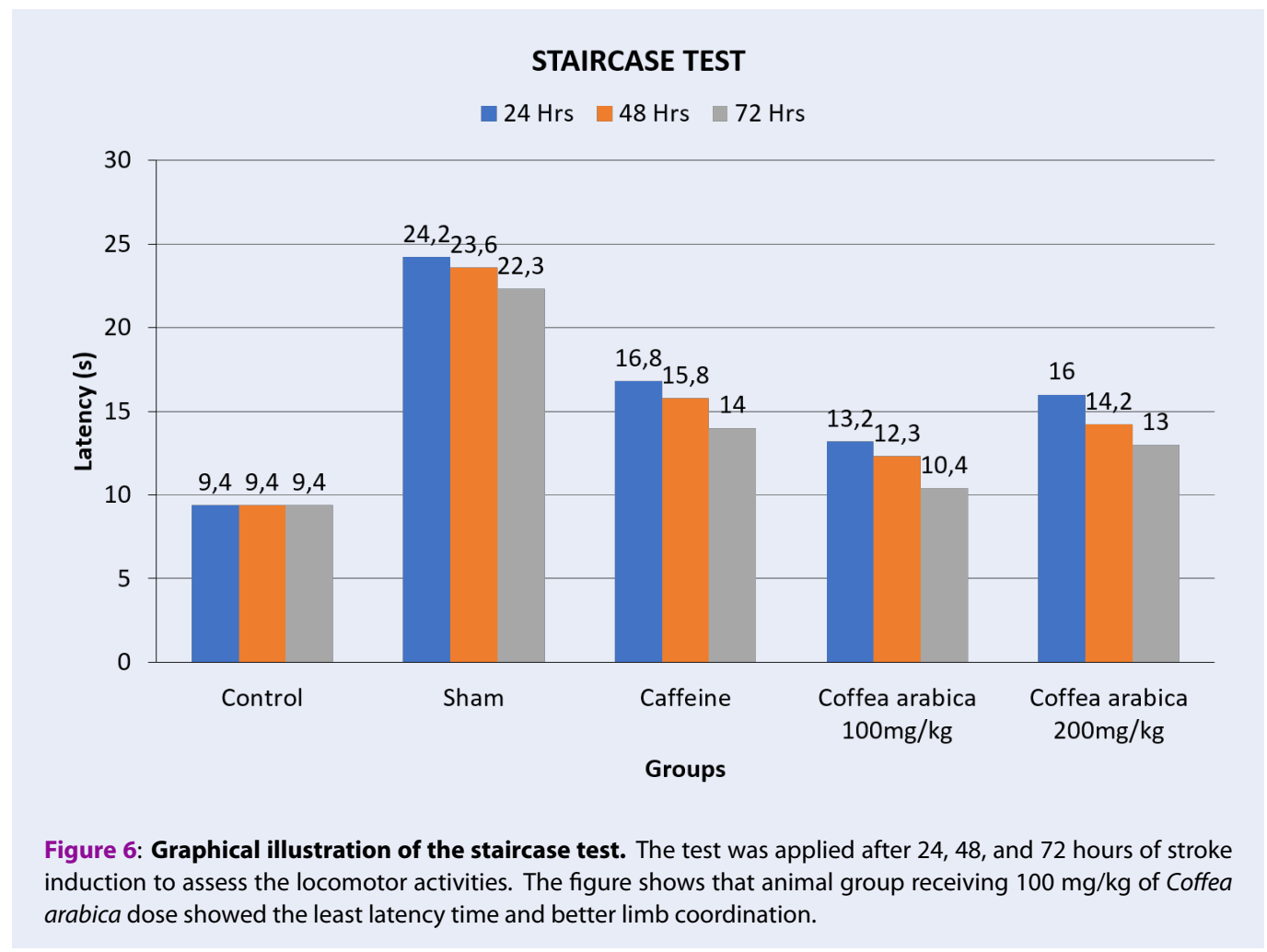




\section{PASTA TEST}

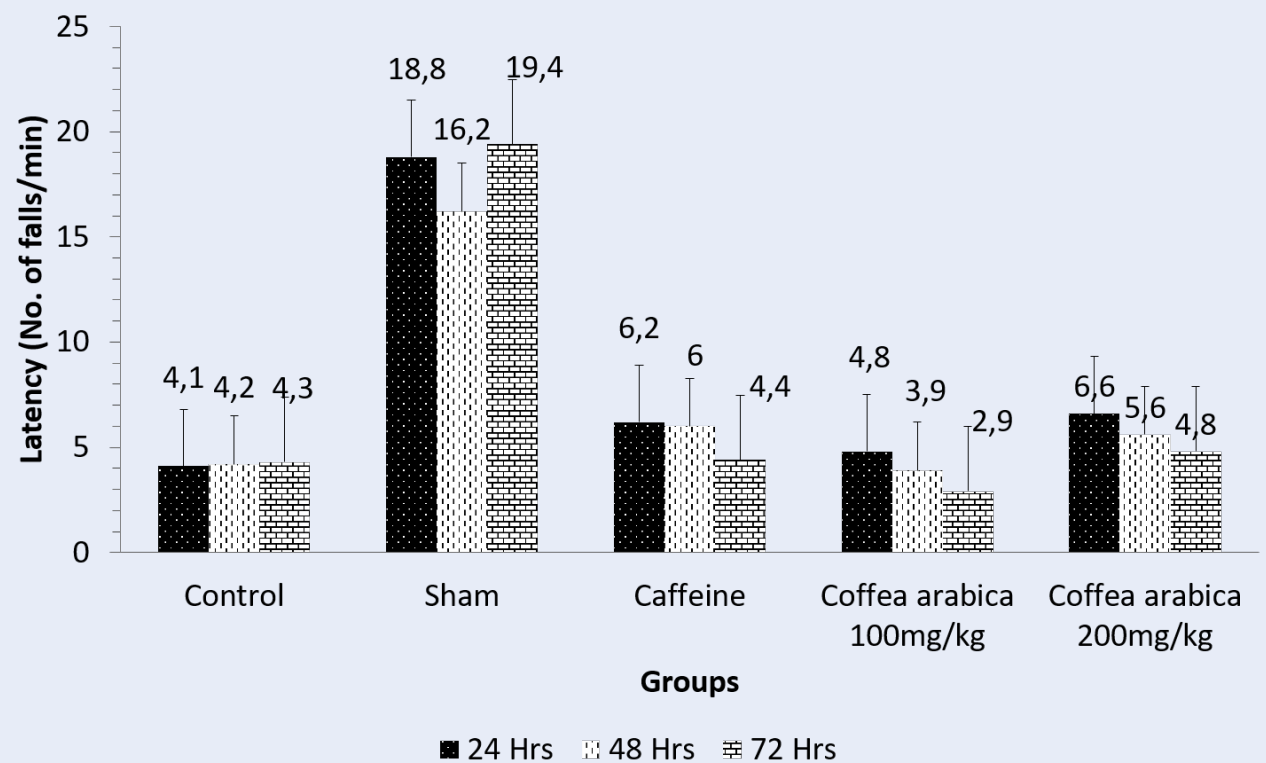

Figure 7: Graphical diagram of pasta test. This test was also applied after 24,48 , and 72 hours of stroke induction in line with other tests to explore the manual dexterity and motor skills. The figure demonstrates that animal group receiving $100 \mathrm{mg} / \mathrm{kg}$ of Coffea arabica dose showed better grasp and grip strength among all defined treatment groups.

and white matter. However, the location, duration, and severity of ischemic stroke need to be considered (Figure 8). Our findings of severe focal ischemia are well-described with characteristic structural changes occurring in both gray and white brain regions, depending on the severity, location, and duration of the ischemic stroke. The white region in our stained brain slice image of the sham group depicted reduced blood flow to the brain, resulting in ischemia. Furthermore, this area was very reduced and compact in the CA 100 $\mathrm{mg} / \mathrm{kg}$ dose group, which depicted functional recovery against ischemic stroke.

\section{DISCUSSION}

The present study aimed to assess the preliminary effects of CA in neuroprotection of experimentallyinduced stroke in rats. Animals were administered with doses of 100 and $200 \mathrm{mg} / \mathrm{kg}$ of CA. The doses of CA were selected based on dose-ranging studies; these are the clinical trials to determine the most appropriate doses that are not exceeding the maximum dose limit or the toxic levels ${ }^{14}$. After the administration of the recommended protocol of 14 days, animals were subjected to induction of ischemic stroke ${ }^{15}$. The subjects were passed through a series of testing procedures for assessing their neurological activity after ex- posure to surgery. These testing procedures included cylinder test, forelimb flexion test, staircase test, and pasta test.

The cylinder test was used to assess the locomotor function in rodents with central nervous system disorders. It was also used to detect mild neurological defects in subjects under study. It was observed during the evaluation that the CA $100 \mathrm{mg} / \mathrm{kg}$ dose showed maximum response against ischemic stroke among all-time intervals (Figure 4). Several studies indicate that coffee is a rich source of flavonoids like catechins and their neuroprotective potential is primarily associated with protection against neurotoxin-induced injuries and suppression of neuro-inflammatory mechanisms, plus the promotion of cognitive functions, learning, and memory ${ }^{16,17}$. The main ingredient in CA neuroprotection is caffeine ${ }^{18-21}$.

A forelimb flexion test was performed to detect the neurological impairments in rodents. Our results indicated that both $100 \mathrm{mg}$ and $200 \mathrm{mg} / \mathrm{kg}$ doses showed significant protective response (Figure 5). However, CA $100 \mathrm{mg} / \mathrm{kg}$ dose was found more effective than 200 $\mathrm{mg} / \mathrm{kg}$ after 24,48 , and 72 hours of post-surgery. A similar study was conducted by Novitzky et al. in 2016 to examine the comparison of the neuroprotective effect of Bevacizumab and Sildenafil after stroke induc- 


\section{Controlled Group}

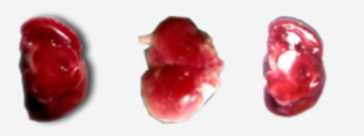

Sham Group

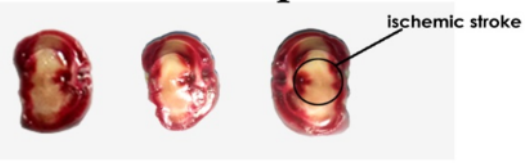

Caffeine

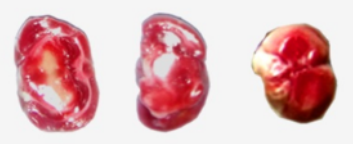

\section{Coffea arabica $100 \mathrm{mg} / \mathrm{kg}$
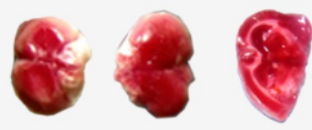

\section{Coffea arabica $200 \mathrm{mg} / \mathrm{kg}$

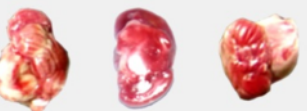

Figure 8: Histopathology of the rat brain. Brain slicing, followed by 2,3,5-Triphenyl tetrazolium chloride staining, was performed to study the histopathological characteristics after 76 hours of ischemic stroke induction. It is clear from the figure that Coffea arabica $100 \mathrm{mg} / \mathrm{kg}$ dose restricted the induction of stroke considerably in association with other treatment protocols.

tion in rodents. The study revealed a minor effect of neuroprotection with Bevacizumab, while Sildenafil showed no response ${ }^{22}$. Conversely, our investigations recognized the healthier connection between paw grasping and brain functions in the rat in association with previous studies.

The staircase test was designed for the exploration of the independent use of forelimbs in rats ${ }^{12}$. Sidespecific deficiencies in coordinated paw reaching in rats were efficiently measured by this test. Our findings exposed that the pharmacological effects of the CA $100 \mathrm{mg} / \mathrm{kg}$ treated group are almost similar to that of the control group (Figure 6). Freret et al. in 2006 used this test to evaluate the above-defined limitations. Our similar findings with that of Freret et al. suggest that CA $100 \mathrm{mg} / \mathrm{kg}$ dose induced more sensi- tive repair efforts, in contrast to the evaluation of contralateral limb use in rats ${ }^{23}$. This finding was also observed by Grabowski et al. with the staircase test, in corroboration with our study ${ }^{24}$.

After experiencing any kind of damage in the central nervous system, manual dexterity is often impaired. Therefore, it is crucial to develop a primary measurement method of forepaw dexterity quantitatively. The pasta test also corroborates with our findings of previous tests. The CA $100 \mathrm{mg} / \mathrm{kg}$ dose was more responsive than caffeine and CA $200 \mathrm{mg} / \mathrm{kg}$ dose (Figure 7). However, the recovery mechanisms might be different according to specific regions of brain damage 25 . For a better understanding of the rehabilitation mechanisms in specific regions of brain damage in rat stroke models, valuable research should continue to examine behavioral tests and functional recovery of stroke so that they discoveries might be translated to human patients of stroke ${ }^{23}$.

The histopathological studies in our study showed typical structural changes in the brain (Figure 8). Our findings of severe focal ischemia are well-described with characteristic structural changes occurring in both gray and white brain regions, depending on the severity, location, and duration of the ischemic stroke. The white region in our stained brain slice image of the sham group depicts the diminished blood flow to the brain that results in ischemia. Furthermore, this area is very reduced and compact in the CA 100 $\mathrm{mg} / \mathrm{kg}$ treated group, demonstrating functional recovery against ischemic stroke. For the evaluation of enhanced plasticity of brain tissue after stroke occurrence, a long-term functional recovery is essential. Neural tissues are complex, and caution should be used in attempting to identify neuroprotective drugs. It was a preliminary study considering only twentyfive subjects on rats. There were two large doses of 100 $\mathrm{mg}$, and $200 \mathrm{mg} / \mathrm{kg}$ were used. Future studies should be carried out on more animal subjects with more refined doses. CA should also be studied in human subjects for its potential medicinal properties.

\section{CONCLUSION}

Our findings conclude that CA is a harmless and active mediator in the dissolution of blood clots and recovery of stroke in rats. It is an agent that is effective at inducing brain activity with few side effects and modifications in behavior. This is because coffee contains many biologically active substances and antioxidants, like polyphenols, that can potentially protect brain cells from death and can help in recovery from stroke. Thus, there is a great need for the evaluation, assessment, and appraisal of its therapeutic characteristics in humans soon. 


\section{ABBREVIATIONS}

CA: Coffea arabica

MCAO: Middle cerebral artery occlusion

TTC: 2,3,5-Triphenyl tetrazolium chloride

ANOVA: Analysis of variance

\section{ACKNOWLEDGMENTS}

I am greatly indebted to my loving parents for their valuable and most precious prayers.

\section{AUTHOR'S CONTRIBUTIONS}

All authors made substantial contributions to conception and design, acquisition of data, or analysis and interpretation of data; took part in drafting the article or revising it critically for important intellectual content; gave final approval of the version to be published; and agree to be accountable for all aspects of the work.

\section{FUNDING}

Not applicable.

\section{AVAILABILITY OF DATA AND MATERIALS}

Data and materials used and/or analysed during the current study are available from the corresponding author on reasonable request.

\section{ETHICS APPROVAL AND CONSENT TO PARTICIPATE}

Not applicable.

\section{CONSENT FOR PUBLICATION}

Not applicable.

\section{COMPETING INTERESTS}

The authors declare that they have no competing interests.

\section{REFERENCES}

1. Millikan C. Animal stroke models. Stroke. 1992;23(6):795797. PMID: 1595094. Available from: https://doi.org/10.1161/ 01.STR.23.6.795.

2. Lo EH, Dalkara T, Moskowitz MA. Mechanisms, challenges, and opportunities in stroke. Nature reviews neuroscience. 2003;4(5):399-414. PMID: 12728267. Available from: https: //doi.org/10.1038/nrn1106.

3. Strong K, Mathers C, Bonita R. Preventing stroke: saving lives around the world. The Lancet Neurology. 2007;6(2):182-187. Available from: https://doi.org/10.1016/S1474-4422(07)700315.

4. Furlan AJ, Katzan IL, Caplan LR. Thrombolytic therapy in acute ischemic stroke. Current treatment options in cardiovascular medicine. 2003;5(3):171-180. PMID: 12777195. Available from: https://doi.org/10.1007/s11936-003-0001-4.
5. Yu M, Sun ZJ, Li LT, Ge HY, Song CQ, Wang AJ. The beneficial effects of the herbal medicine Di-huang-yin-zi (DHYZ) on patients with ischemic stroke: a randomized, placebocontrolled clinical study. Complementary therapies in medicine. 2015;23(4):591-597. PMID: 26275652. Available from: https://doi.org/10.1016/j.ctim.2015.06.003.

6. Pandian JD, Liu M, Misbach J, Venketasubramanian N. Alternative therapies for stroke treatment in Asia. International Journal of Stroke. 2011;6(6):541-543. PMID: 22111799. Available from: https://doi.org/10.1111/j.1747-4949.2011.00680.x.

7. Ky CL, Louarn J, Dussert S, Guyot B, Hamon S, Noirot M. Caffeine, trigonelline, chlorogenic acids, and sucrose diversity in wild Coffea arabica L. and C. canephora P. accessions. Food chemistry. 2001;75(2):223-230. Available from: https://doi. org/10.1016/S0308-8146(01)00204-7.

8. Castro MME, Pereira RGFA, Dias DF, Gontijo VS, Vilela FC, Moraes GOI, et al. Anti-inflammatory effect of aqueous extracts of roasted and green Coffea arabica L. Journal of functional foods. 2013;5(1):466-474. Available from: https://doi. org/10.1016/j.jff.2012.12.002.

9. Rizvi S, Jaiswal V, Mukerji D, Mathur S. Antifungal properties of 1, 3, 7-trimethylxanthine, isolated from Coffea arabica. Naturwissenschaften. 1980;67(9):459-460. PMID: 7422010. Available from: https://doi.org/10.1007/BF00405645.

10. Tamura A, Graham D, McCulloch J, Teasdale G. Focal cerebral ischaemia in the rat: 1 . Description of technique and early neuropathological consequences following middle cerebral artery occlusion. Journal of Cerebral Blood Flow \& Metabolism. 1981;1 (1):53-60. PMID: 7328138. Available from: https://doi.org/10.1038/jcbfm.1981.6.

11. Gharbawie OA, Whishaw PA, Whishaw IQ. The topography of three-dimensional exploration: a new quantification of vertical and horizontal exploration, postural support, and exploratory bouts in the cylinder test. Behavioural brain research. 2004;151(1-2):125-135. PMID: 15084428. Available from: https://doi.org/10.1016/j.bbr.2003.08.009.

12. Montoya C, Campbell-Hope L, Pemberton K, Dunnett S. The "staircase test": a measure of independent forelimb reaching and grasping abilities in rats. Journal of neuroscience methods. 1991;36(2-3):219-228. Available from: https://doi.org/10. 1016/0165-0270(91)90048-5.

13. Ballermann M, Metz GA, McKenna JE, Klassen F, Whishaw IQ. The pasta matrix reaching task: a simple test for measuring skilled reaching distance, direction, and dexterity in rats. Journal of neuroscience methods. 2001;106(1):39-45. Available from: https://doi.org/10.1016/S0165-0270(01)00326-0.

14. Ting AH, McGarvey KM, Baylin SB. The cancer epigenomecomponents and functional correlates. Genes \& development. 2006;20(23):3215-3231. PMID: 17158741. Available from: https://doi.org/10.1101/gad.1464906.

15. Ginsberg MD. Adventures in the pathophysiology of brain ischemia: penumbra, gene expression, neuroprotection: the 2002 Thomas Willis Lecture. Stroke. 2003;34(1):214-223. PMID: 12511777. Available from: https://doi.org/10.1161/01. STR.0000048846.09677.62.

16. Zhang R, Wang Y, Zhang L, Zhang Z, Tsang W, Lu M, et al. Sildenafil (Viagra) induces neurogenesis and promotes functional recovery after stroke in rats. Stroke. 2002;33(11):2675-2680. PMID: 12411660. Available from: https://doi.org/10.1161/01. STR.0000034399.95249.59.

17. Zhao X, Liu SJ, Zhang J, Strong R, Aronowski J, Grotta JC. Combining insulin-like growth factor derivatives plus caffeinol produces robust neuroprotection after stroke in rats. Stroke. 2005;36(1):129-134. PMID: 15569874. Available from: https: //doi.org/10.1161/01.STR.0000149624.87661.18.

18. Trinh K, Andrews L, Krause J, Hanak T, Lee D, Gelb M, et al. Decaffeinated coffee and nicotine-free tobacco provide neuroprotection in Drosophila models of Parkinson's disease through an NRF2-dependent mechanism. Journal of Neuroscience. 2010;30(16):5525-5532. PMID: 20410106. Available from: https://doi.org/10.1523/JNEUROSCI.4777-09.2010. 
19. Yan R, Zhang J, Park HJ, Park ES, Oh S, Zheng H, et al. Synergistic neuroprotection by coffee components eicosanoyl-5hydroxytryptamide and caffeine in models of Parkinson's disease and DLB. Proceedings of the National Academy of Sciences. 2018;115(51):E12053-E12062. PMID: 30509990. Available from: https://doi.org/10.1073/pnas.1813365115.

20. $\mathrm{Xu} \mathrm{K}, \mathrm{Xu} \mathrm{YH}$, Chen JF, Schwarzschild MA. Caffeine's neuroprotection against 1-methyl-4-phenyl-1, 2, 3, 6-tetrahydropyridine toxicity shows no tolerance to chronic caffeine administration in mice.

Neuroscience letters. 2002;322(1):13-16. Available from: https://doi.org/10.1016/S0304-3940(02)00069-1.

21. Chen JF, Xu K, Petzer JP, Staal R, Xu YH, Beilstein M. Neuroprotection by caffeine and $\mathrm{A} 2 \mathrm{~A}$ adenosine receptor inactivation in a model of Parkinson's disease. Journal of Neuroscience. 2001:21(10):RC143-RC. PMID: PMCid:PMC6762498. Available from: https://doi.org/10.1523/JNEUROSCI.21-10-j0001.2001.
22. Novitzky I, Marianayagam NJ, Weiss S, Muhsinoglu O, Fridman M, Leibovitch TA, et al. Comparison of neuroprotective effect of bevacizumab and sildenafil following induction of stroke in a mouse model. BioMed research international. 2016;Available from: https://doi.org/10.1155/2016/ 3938523PMid:27314018.

23. Freret $\mathrm{T}$, Bouet V. Improvements of the stroke model guidelines-animal body weight and long-term functional concerns. J Exp Stroke TransI Med. 2009;2(2):28-31. Available from: https://doi.org/10.6030/1939-067X-2.2.28.

24. Grabowski M, Brundin P, Johansson BB. Paw-reaching, sensorimotor, and rotational behavior after brain infarction in rats. Stroke. 1993;24(6):889-895. PMID: 8506561. Available from: https://doi.org/10.1161/01.STR.24.6.889.

25. Barth PG. Pontocerebellar hypoplasia-how many types? European Journal of Paediatric Neurology. 2000;4(4):161-162. PMID: 11008257. Available from: https://doi.org/10.1053/ejpn. 2000.0294 . 